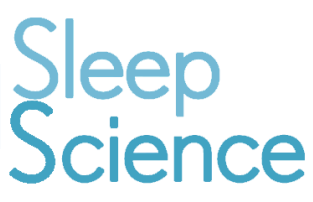

\title{
Assessment of sleep quality and its association with problematic internet use among university students: a cross- sectional investigation in Bangladesh
}

\author{
Zohurul Islam $^{1}$ \\ Kamrul Hsan ${ }^{1}$ \\ Saiful Islam ${ }^{1 *}$ \\ David Gozal ${ }^{1,2}$ \\ Mahfuz Hossain ${ }^{1}$
}

${ }^{1}$ Jahangirnagar University, Department of Public Health and Informatics - Savar Dhaka - Bangladesh.

${ }^{2}$ University of Missouri School of Medicine, Department of Child Health, and the Child Health Research Institute Columbia - Missouri - United States.
*Corresponding author: Saiful Islam

E-mail: saiful@phiju.edu.bd

Received: September 26, 2020; Accepted: November 9, 2020.

\begin{abstract}
Objectives: Problematic internet use (PIU) is a major behavioral problem that has been closely associated with poor sleep quality in many different countries, but is poorly studied in Bangladesh. This study was conducted to investigate the sleep quality and its association with PIU among university students in Bangladesh. Material and Methods: A cross-sectional study was conducted between May 2019 and December 2019 among 400 students attending four public universities in Bangladesh. The Pittsburgh sleep quality index (PSQI) was used to determine sleep quality and Young's internet addiction test (IAT) was used to describe the degree of PIU. Results: A significant negative association emerged between good sleep quality and PIU $(\mathrm{p}<0.001)$. In the multivariate logistic regression, students having PIU were 0.28 folds less likely to have good sleep quality (AOR: $0.28,95 \% \mathrm{CI}=0.18-0.43, \mathrm{p}<0.001)$ when compared to non-PIU students. In addition, significant associations between sleep quality and socio-demographic and lifestyle factors were identified. Conclusion: Implementation of an effective awareness program and development of education strategies are required to reduce internet addictive behaviors and improve sleep quality among Bangladeshi university students.
\end{abstract}

Keywords: Sleep Quality; Problematic Internet Use; Internet Addiction; University Students; Bangladesh. 


\section{INTRODUCTION}

It is quite obvious that nowadays, access and use of the internet have become an essential element of everyday life $^{1}$, being widely used for entertainment, communication, and education. Globally, internet use has grown exponentially to more than 2.5 billion active users with a majority being adolescents and younger people ${ }^{2}$. Despite the inherent advantages afforded by internet use, excessive and uncontrolled use has become a significant social and behavioral problem. Such problematic internet use (PIU) has been termed "internet addiction" (IA) and has been traditionally defined as excessive or poorly controlled preoccupations, urges or behaviors regarding computer use and internet access that lead to impairment or distress $^{3}$ and its prevalence varies greatly depending on the population being studied ${ }^{1,4-9}$.

A previous study showed that students who excessively use the internet have a greater likelihood of experiencing sleep problems, and are more likely to suffer from psychological problems than those who do not ${ }^{10}$. Some of the consequences of IA include depression, anxiety, stress, sleep disturbances, bad temper, restlessness, as well as problems regarding social relationships and educational achievements ${ }^{5,11-13}$. A previous study found that IA and other PIU behaviors possibly impose significant influences on the sleep-wake schedule, leading to the emergence of insomnia and other sleep disturbances ${ }^{12}$. A study conducted among Chinese high school students reported that the prevalence of PIU was $17.2 \%$ among students, with $40 \%$ of students suffering from sleep disturbances, and up to $51.4 \%$ of students exhibiting depressive symptoms ${ }^{14}$. In Bangladesh, the prevalence of PIU was $24 \%$ among university students, with $25 \%$ of students suffering from short sleep ${ }^{15}$.

Sleep is one of the pillars of health and is a life-sustaining function ${ }^{5,16,17}$. Quality and sufficient sleep is necessary for both physical and mental health ${ }^{5,13,18,19}$, while poor sleep quality or insufficient sleep are closely associated with unhealthy lifestyle behaviors including internet use ${ }^{20}$. Indeed, excessive internet usage is a leading predictor of poor sleep quality and negligence at work $^{21}$. Furthermore, students with internet addiction in China exhibit 1.73 times higher risk of poor sleep quality compared to other students ${ }^{22}$.

Sleep is also essential for cognitive functions related to academic performance in higher education ${ }^{23-29}$. In a previous study, $69.7 \%$ of college students with lower grade point average (GPA) had difficulty in falling asleep ${ }^{30}$. In Bangladesh, the "Digital Bangladesh" movement was launched for the promotion of information technology by the current government. Therefore, the number of internet subscribers has increased during the last few years after launching the movement, with 12.7 million new users within a single year ${ }^{31}$. Consequently, we are likely to witness the accelerated emergence of PIU and poor sleep quality in Bangladesh in the upcoming years. A recently published study found that the prevalence of poor sleep quality among the Bangladeshi university students is $66.6 \% 0^{32}$, while another study reported a prevalence of $69.5 \%$ among Bangladeshi medical college students ${ }^{13}$. Although a few studies have been conducted to investigate PIU among university students ${ }^{15,31,33,34}$, there are limited studies that evaluated potential associations between PIU and sleep quality ${ }^{13}$. Consequently, the study aimed to investigate the sleep quality and its association with PIU among university students in Bangladesh.

\section{MATERIAL AND METHODS}

\section{Study setting and population}

A cross-sectional study was conducted in four public universities (Jahangirnagar University, University of Rajshahi, Bangabandhu Sheikh Mujibur Rahman Agricultural University, and Noakhali Science \& Technology University) located in Bangladesh, from May 2019 to December 2019. We recruited 400 students who met the inclusion criteria including: (1) age from 18 to 26 years; (2) regular enrolled university students; (3) having access to at least a social networking site; and (4) actively using the internet. Participants were fully voluntary and uncompensated.

\section{Data collection tools and technique}

Data were collected through anonymous survey using a self-reported Bangla questionnaire (as participants' first language was Bangla) consisting of three sections. Section 1 comprised questions related to socio-demographic and lifestyle variables, including age, sex, marital status, place of residence during class (living with family at home or dormitory), parents' monthly income, father's occupation, mother's occupation, number of siblings, urban or rural residence prior to university, physical activity (regular or irregular), brushing of teeth before sleep (yes or no). Section 2 comprised questions to assess the degree of PIU among the university students via the Pittsburgh sleep quality index (PSQI) and section 3 comprised questions to assess sleep quality using the internet addiction test (IAT). We implemented a convenient sampling approach to recruit the study participants. Initially, 430 datasets were collected after obtaining informed consent. Of these, 400 were included in the final analysis based on inclusion criteria along with the removal of incomplete or data missing surveys.

\section{Pittsburgh sleep quality index (PSQI)}

The PSQI is a parameter-based questionnaire relying on self-reported responses, and was first developed by Buysse et al. $(1989)^{35}$, it is one of the popular tools for the assessment of sleep quality. PSQI consists of 19 items questions, which are grouped into seven components (i.e., subjective sleep quality, sleep latency, sleep duration, habitual sleep efficiency, use of sleep medication, and daytime dysfunction) assessed features of sleep quality over the last month ${ }^{35}$, each weighted equally on a $0-3$ scale. The seven components scores are then summed to yield a global PSQI score of sleep quality between 0 and 21. A higher score indicates poor sleep quality ${ }^{35}$. The present study evaluated sleep quality among the participants by using the validated Bangla version of the PSQI, which is also called the Bengali Pittsburgh 
sleep quality index (BPSQI) ${ }^{36}$. A BPSQI score $>5$ was selected as the cut-off for the poor sleep quality ${ }^{36,37}$.

\section{Internet addiction test (IAT)}

The IAT is a psychometric screening tool for assessing problematic internet use, developed by Young $(1998)^{38}$ which is the first validated and reliable measure of the addictive use of internet $t^{5,34}$ measuring psychological dependence, compulsive use, and withdrawal, as well as related problems of school, sleep, family, and time management ${ }^{4}$. In the present study, we utilized the validated Bangla version of IAT $^{34}$, which consists of 18 questions (e.g., How often do you find that you stay online longer than you intended?) with a five-point Likert scale ranging from 1 (rarely) to 5 (always). The validated Bangla version of IAT $^{34}$ showed very good internal consistency (Cronbach's $\alpha=.89$ ), and strong convergent and discriminant validity. The total score is obtained by summating the raw score of each construct ranging from 18 to $90^{34}$, with the higher the score indicating the greater the level of problematic internet use. The level of internet use was categorized into three groups as minimal, moderate, and excessive users based the 18-item Bangla IAT scoring 18-35, 3662 , and 63-90, respectively ${ }^{34}$. In the present study, those scoring moderate to excessive scores $(\geq 36)$ were classified as PIU $^{34}$.

\section{Statistical analysis}

Data were analyzed using the Statistical Package for Social Science (SPSS) software version 25.0. Statistical analyses included descriptive statistics (e.g., frequencies, percentages, means, Chi-square test and Fisher's exact test). Categorical variables were compared between two groups "good sleep quality" vs. "poor sleep quality". Logistic regression (both unadjusted and adjusted models) was performed with 95\% confidence intervals to determine significant associations between categorical dependent and independent variables. Analyses were univariate, crude odds ratios (COR) of all examined variables (independent) were compared with sleep quality as the dependent variable. Multivariable analyses were also performed with all variables combined in the model as covariates to yield adjusted odds ratios (AOR) where the dependent variable included sleep quality. A $p$-value of less than 0.05 was considered as statistically significant.

\section{Ethical considerations}

This study was approved by the Biosafety, Biosecurity and Ethical Committee of the Jahangirnagar University, Savar, Dhaka-1342, Bangladesh [Ref. No.: BBEC, JU/M2020 (2)2]. Informed written consent was obtained from all the participants prior to data collection. The objectives of the research were explained to the participants and they were informed that they could choose to participate (or not) in the study. Only after getting their permission to participate in the study, they were surveyed. Strict confidentiality of information and anonymity to the participants was ensured.

\section{RESULTS}

400 university students aged 18-26 years of which 279 $(69.8 \%)$ were male completed the survey. The average age of participants was 21.2 years $(\mathrm{SD}=1.8)$ and most of the participants came from rural areas $(61.5 \%)$. Most of the participants were single $(94.3 \%)$ and stayed in the university student dormitory (64.3\%); $86 \%$ were non-smokers, $80.3 \%$ did not perform physical exercise regularly, and $51.2 \%$ were not brushing teeth before sleep. Of the respondents, $67.3 \%$ had access to internet through mobile, $11 \%$ through laptop, and $21.8 \%$ through both devices. Based on IAT scores, the prevalence rates of minimal, moderate, and excessive users were $46.0 \%, 47.8 \%$, and $6.3 \%$, respectively, that indicating $54 \%$ participants fulfilled the criteria as PIU. In addition, $51.5 \%$ of study participants reported good sleep quality (Table 1).

There were no significant differences between sleep quality and age groups, gender, marriage status, residence location and origin, physical activity, smoking habits, or other demographic factors. However, participants' sleep quality was associated with their mothers' occupation $\left(\chi^{2}=6.67, \mathrm{df}=1\right.$, $p=0.01)$ and internet use $\left(\chi^{2}=36.85, \mathrm{df}=1, p<0.001\right)$ (Table 2).

Bivariate and multivariate logistic regression analyses were performed and the unadjusted and adjusted odds ratios are shown in Table 3. In the unadjusted model, students having PIU were 0.28 times less likely to have good sleep quality than non-PIU (AOR: $0.28,95 \% \mathrm{CI}=0.19-0.43, p<0.001$ ). In addition, the adjusted model indicated that PIU was negatively associated with good sleep quality. Students reporting PIU were $28 \%$ less likely to have good sleep quality (AOR: 0.28 ; $95 \% \mathrm{CI}=0.18-0.43$, $p<0.001$ ) when compared to non-PIU. The model also indicated that the respondents whose mother was a housewife were $50 \%$ less likely to have good sleep quality than respondents whose mother was employed (COR: $0.50,95 \% \mathrm{CI}=0.29-0.85, p=0.011$ ) but this was insignificant in adjusted model (Table 3).

\section{DISCUSSION}

The present study showed that the presence of PIU and poor sleep quality is highly prevalent and correlated among university students in Bangladesh. Evidence suggests that PIU is significantly associated with depression, poor sleep quality, mood changes, and unfavorable health outcomes, such as obesity and low self-esteem ${ }^{34,39}$. Students who use internet excessively have an increased chance of experiencing sleep problems ${ }^{26}$. Therefore, sleep disturbances among university students are not only more likely to occur but carry also a potentially significant burden among students who spend excessive hours surfing the internet ${ }^{5}$. Although a few studies have already investigated the prevalence of PIU among university students in Bangladesh ${ }^{15,31,3,3,34}$, studies assessing the association between PIU and sleep quality are very limited ${ }^{13}$.

The prevalence of poor sleep quality in the present study was comparatively lower than in the only other study in Bangladesh, which reported poor sleep quality in $69.5 \%$ of 
Table 1. Socio-demographic and lifestyle factors among 400 university students.

\begin{tabular}{|c|c|c|c|}
\hline Variables & Categories & Frequency & Percentage $(\%)$ \\
\hline \multirow[t]{3}{*}{ Age } & $18-20$ & 167 & $(41.8)$ \\
\hline & $21-23$ & 181 & $(45.3)$ \\
\hline & $24-26$ & 52 & $(13.0)$ \\
\hline \multirow[t]{2}{*}{ Sex } & Male & 279 & $(69.8)$ \\
\hline & Female & 121 & $(30.3)$ \\
\hline \multirow[t]{2}{*}{ Marital status } & Married & 23 & $(5.8)$ \\
\hline & Single & 377 & $(94.3)$ \\
\hline \multirow[t]{2}{*}{ Place of residence } & Home & 143 & $(35.8)$ \\
\hline & Hall & 257 & $(64.3)$ \\
\hline \multirow[t]{5}{*}{ Father's occupation } & Services & 173 & $(43.3)$ \\
\hline & Businessman & 95 & $(23.8)$ \\
\hline & Farmer & 99 & $(24.8)$ \\
\hline & Immigrant & 6 & $(1.5)$ \\
\hline & Dead & 27 & $(6.8)$ \\
\hline \multirow[t]{2}{*}{ Mother's occupation } & Housewife & 328 & $(82.0)$ \\
\hline & Employed & 61 & $(18.0)$ \\
\hline \multirow[t]{2}{*}{ Monthly family income } & $<50000$ BDT & 340 & $(85.0)$ \\
\hline & $>50000 \mathrm{BDT}$ & 60 & $(15.0)$ \\
\hline \multirow[t]{3}{*}{ No of siblings } & $1-3$ & 303 & $(75.8)$ \\
\hline & $4-6$ & 90 & $(22.5)$ \\
\hline & $>7$ & 7 & $(1.8)$ \\
\hline \multirow[t]{2}{*}{ Came from } & Rural area & 246 & $(61.5)$ \\
\hline & Urban area & 154 & $(38.5)$ \\
\hline \multirow[t]{3}{*}{ Internet browsing device } & Mobile & 269 & $(67.3)$ \\
\hline & Laptop & 44 & $(11.0)$ \\
\hline & Both devices & 87 & $(21.8)$ \\
\hline \multirow[t]{2}{*}{ Smoking habits } & Yes & 56 & $(14.0)$ \\
\hline & No & 344 & $(86.0)$ \\
\hline \multirow[t]{2}{*}{ Physical activity } & Regular & 79 & $(19.8)$ \\
\hline & Irregular & 321 & $(80.3)$ \\
\hline \multirow[t]{2}{*}{ Brushing teeth before sleep } & Yes & 195 & $(48.8)$ \\
\hline & No & 205 & $(51.2)$ \\
\hline \multirow[t]{2}{*}{ Internet use } & Non-PIU & 184 & $(46.0)$ \\
\hline & PIU & 216 & $(54.0)$ \\
\hline \multirow[t]{2}{*}{ Sleep quality } & Good & 206 & $(51.5)$ \\
\hline & Poor & 194 & $(48.5)$ \\
\hline
\end{tabular}

Note: BDT $=$ Bangladeshi Taka.

medical students ${ }^{13}$. Similarly, Afandi et al. $(2017)^{40}$ reported poor sleep quality in $67.2 \%$ of university students in the United Arab Emirates (UAE). The reasons for such discrepant findings are unclear but could reflect both the type of students (medical vs. others) or the differences in overall ease of access to the internet in different countries. The majority of the respondents in the present study were moderate internet users (36.8\%), with $6.3 \%$ being considered excessive internet users. Differences in the frequency of PIU among university students have been reported in different studies in Bangladesh, whereby Karim and Nigar (2014) $)^{34}$ found only $1.7 \%$ as being excessive users, while and Islam and Hossin $(2016)^{15}$, found that $24 \%$ were problematic users (i.e., either moderate or excessive internet users) and Mamun et al. (2019) ${ }^{31}$ found that 3.9\% of graduate students were excessive internet users ${ }^{15,31,34}$. Thus, the escalation of the number of users over the years and the overall duration of use could have contributed to the differences across the various studies.

The proportion of poor sleep quality among male university students was higher than among female students, although there is no significant gender difference regarding overall sleep quality. Other studies conducted in Turkey ${ }^{41}$ and Bangladesh $^{13}$ also found a higher prevalence of poor sleep quality among male students. Students whose mothers were 
Table 2. Associations between socio-demographic and lifestyle factors, internet use, and sleep quality among university students $(\mathrm{N}=400)$.

\begin{tabular}{|c|c|c|c|c|c|c|c|c|}
\hline \multirow{3}{*}{ Variables } & \multirow{3}{*}{ Categories } & \multicolumn{4}{|c|}{ Sleep quality } & \multirow[t]{3}{*}{$\chi^{2}$} & \multirow[t]{3}{*}{$d f$} & \multirow[t]{3}{*}{$p$-value } \\
\hline & & \multicolumn{2}{|c|}{ Poor } & \multicolumn{2}{|c|}{ Good } & & & \\
\hline & & $\mathrm{n}$ & $(\%)$ & $\mathrm{n}$ & $(\%)$ & & & \\
\hline \multirow[t]{3}{*}{ Age (years) } & $18-20$ & 80 & $(41.2)$ & 87 & $(42.2)$ & 0.247 & 2 & 0.884 \\
\hline & $21-23$ & 90 & $(46.4)$ & 91 & $(44.2)$ & & & \\
\hline & $24-26$ & 24 & $(12.4)$ & 28 & $(13.6)$ & & & \\
\hline \multirow[t]{2}{*}{ Sex } & Male & 143 & (73.7) & 136 & $(66.0)$ & 2.802 & 1 & 0.094 \\
\hline & Female & 51 & $(26.3)$ & 70 & $(34.0)$ & & & \\
\hline \multirow[t]{2}{*}{ Marital status } & Married & 13 & $(6.7)$ & 10 & $(4.9)$ & 0.629 & 1 & 0.428 \\
\hline & Single & 181 & $(93.3)$ & 196 & $(95.1)$ & & & \\
\hline \multirow[t]{2}{*}{ Place of residence } & With family at home & 78 & $(40.2)$ & 65 & (31.6) & 3.257 & 1 & 0.071 \\
\hline & Dormitory & 116 & $(59.8)$ & 141 & $(68.4)$ & & & \\
\hline \multirow[t]{5}{*}{ Father's occupation } & Services & 78 & $(40.2)$ & 95 & $(46.1)$ & $2.216 \dagger$ & 4 & 0.706 \\
\hline & Businessman & 49 & $(25.3)$ & 46 & $(22.3)$ & & & \\
\hline & Farmer & 51 & $(26.3)$ & 48 & $(23.3)$ & & & \\
\hline & Immigrant & 2 & $(1.0)$ & 4 & $(1.9)$ & & & \\
\hline & Dead & 14 & $(7.2)$ & 13 & $(6.3)$ & & & \\
\hline \multirow[t]{2}{*}{ Mother's occupation } & Housewife & 169 & $(87.1)$ & 159 & $(77.2)$ & 6.673 & 1 & 0.010 \\
\hline & Employed & 25 & $(12.9)$ & 47 & $(22.8)$ & & & \\
\hline \multirow[t]{2}{*}{ Monthly family income } & $<50000 \mathrm{BDT}$ & 169 & $(87.1)$ & 171 & $(83.0)$ & 1.320 & 1 & 0.251 \\
\hline & $>50000 \mathrm{BDT}$ & 25 & $(12.9)$ & 35 & $(17.0)$ & & & \\
\hline \multirow[t]{3}{*}{ No of siblings } & $1-3$ & 148 & (76.3) & 155 & $(75.2)$ & $0.182 \dagger$ & 2 & 0.973 \\
\hline & $4-6$ & 43 & $(22.2)$ & 47 & $(22.8)$ & & & \\
\hline & $>7$ & 3 & $(1.5)$ & 4 & $(1.9)$ & & & \\
\hline \multirow[t]{2}{*}{ Came from } & Rural area & 120 & $(61.9)$ & 126 & $(61.2)$ & 0.020 & 1 & 0.887 \\
\hline & Urban area & 74 & $(38.1)$ & 80 & $(38.8)$ & & & \\
\hline \multirow[t]{3}{*}{ Internet browsing device } & Mobile & 127 & $(65.5)$ & 142 & $(68.9)$ & 3.325 & 2 & 0.190 \\
\hline & Laptop & 18 & $(9.3)$ & 26 & (12.6) & & & \\
\hline & Both devices & 49 & $(25.3)$ & 38 & $(18.4)$ & & & \\
\hline \multirow[t]{2}{*}{ Smoking habits } & Yes & 29 & $(14.9)$ & 27 & $(13.1)$ & 0.281 & 1 & 0.596 \\
\hline & No & 165 & $(85.1)$ & 179 & $(86.9)$ & & & \\
\hline \multirow[t]{2}{*}{ Physical activity } & Regular & 37 & $(19.1)$ & 42 & (20.4) & 0.109 & 1 & 0.741 \\
\hline & Irregular & 157 & $(80.9)$ & 164 & $(79.6)$ & & & \\
\hline \multirow[t]{2}{*}{ Brushing teeth before sleep } & Yes & 97 & $(50.0)$ & 98 & $(47.6)$ & 0.236 & 1 & 0.627 \\
\hline & No & 97 & $(50.0)$ & 108 & $(52.4)$ & & & \\
\hline \multirow[t]{2}{*}{ Internet use } & Non-PIU & 59 & $(30.4)$ & 125 & $(60.7)$ & 36.847 & 1 & $<0.001$ \\
\hline & PIU & 135 & $(69.6)$ & 81 & $(39.3)$ & & & \\
\hline
\end{tabular}

homemakers and were not in paid employment were less likely to have good sleep quality than employed mothers, which supports the prior findings ${ }^{13}$. Elucidation of this particular issue will have to await additional studies.

In this study, we found a significant association between PIU and sleep quality among university students, suggesting that increasing or excessive internet use may favor the emergence of poor sleep quality. Of note, a prior Bangladeshi study conducted among medical college students reported a significant negative association between PIU and good sleep quality ${ }^{13}$. However, the findings of this study were subsequently criticized due to methodological limitations that involved the fact that the English language instrument (i.e., the Orman's Internet
Addiction Survey): (i) was never published in a peer-reviewed journal; (ii) never underwent any psychometric testing (not even basic reliability or validity checks); (iii) has cut-off scores that have never been subjected to specificity or sensitivity analyses; and (iv) was developed over two decades ago and is therefore outdated $^{42}$. The reason for this finding could be that increased internet use leads to virtual connectivity with more individuals via Facebook, WeChat, WhatsApp Twitter, LinkedIn, and other online social media, which in turn enhances further reliance on the internet, with such time on the internet displacing sleep.

In addition, increased internet use could increase spending time reading online news and watching videos on YouTube, also displacing sleep. Our findings are concurrent with other studies 
Table 3. Bivariate and multivariate analysis of factors associated with sleep quality.

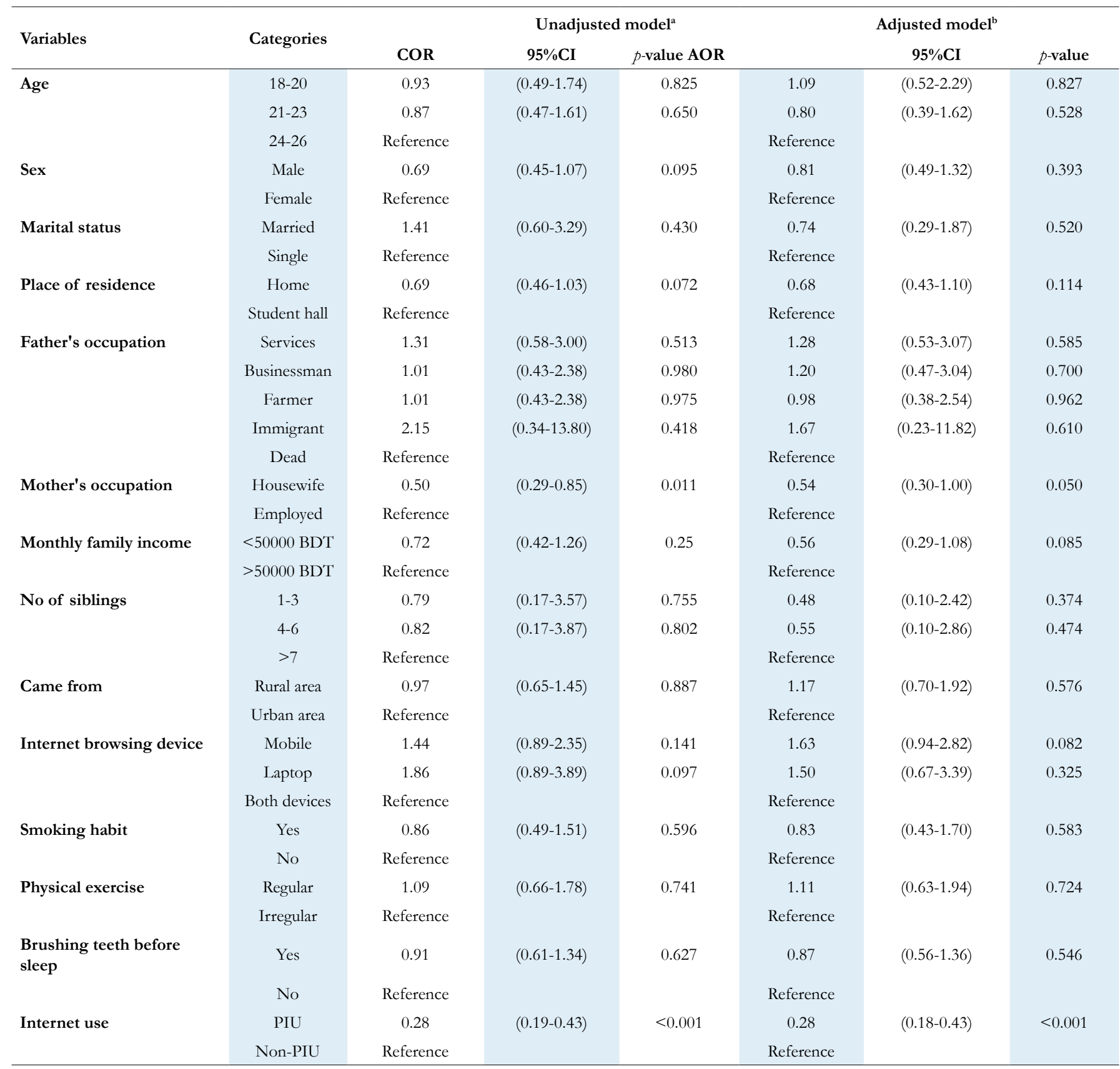

Notes: $\mathrm{BDT}=$ Bangladeshi Taka; $\mathrm{COR}$ = Crude Odds Ratio; CI = Confidence Interval; AOR = Adjusted Odds Ratio. ${ }^{\mathrm{a}}$ Unadjusted Model: Dependent variable: Sleep quality; Independent variables: Age, Sex, Marital status, Place of residence, Father's occupation, Mother's occupation, Monthly family income, No of siblings, Came from, Internet

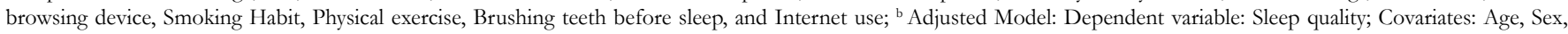
Marital status, Place of residence, Father's occupation, Mother's occupation, Monthly family income, No of siblings, Came from, Internet browsing device, Smoking Habit, Physical exercise, Brushing teeth before sleep, and Internet use.

around the world that also found significant associations between PIU and sleep quality among students $2,5,13,20,22,43,44$. A study in Taiwanese college students also reported that poor sleep quality was 1.4 folds more likely to be experienced by those students with PIU ${ }^{45}$. Similarly, it has been reported that most students with sleep problems will be spending more time online and watching television ${ }^{46}$.

The study will help to explore the research gap more rigorously in different settings, and results from such studies should inform new policies regarding how Bangladeshi university students' sleep characteristics are being affected by problematic internet use. Current findings suggest that an immediate intervention to this vulnerable group aimed at improving sleep quality by reducing problematic internet use should be beneficial. However, systematic online counseling, education leading to increased awareness, and methodologies aimed at improving motivation need to be developed in this respect.

\section{Strengths and limitations}

This study is one of the few reporting on the association between sleep and PIU, and used previously validated tools to 
this effect. However, the study is limited by the use of selfreported information regarding internet use or sleep problems which might have influenced the results through well-known biases (i.e., memory recall biases and social desirability biases). Furthermore, the study was cross-sectional in nature, and therefore cannot provide any indication of causality. The study was also limited by relatively a small sample size, and it was conducted at only four Universities in Bangladesh; therefore, generalizability to other university samples (and other types of student populations) in the country may be limited. Future studies should overcome such limitations by employing longitudinal designs with larger and more representative samples.

\section{CONCLUSION}

PIU and reduced sleep quality among university students in Bangladesh are likely to co-exist and potentially lead to adverse consequences regarding health and academic performance. Implementation of effective awareness programs and the development of education strategies for university students appear to be highly advisable to attenuate the impact of internet addiction and improve sleep quality among university students.

\section{ACKNOWLEDGMENTS}

The authors would like to thank the Department and all the participants of the study for their cooperation without whom, this work would have never been accomplished.

\section{FUNDING}

This study was funded by the University Grand Commission (UGC) of Bangladesh.

\section{CONFLICT OF INTEREST}

Authors have no conflicts of interest to declare.

\section{REFERENCES}

1. Do KY, Lee KS. Relationship between problematic internet use, sleep problems, and oral health in Korean adolescents: a national survey. Int J Environ Res Public Health. 2018 Sep;15(9):1870.

2. Younes F, Halawi G, Jabbour H, El Osta N, Karam L, Hajj A, et al. Internet addiction and relationships with insomnia, anxiety, depression, stress and self-esteem in university students: a cross-sectional designed study. PLoS One. 2016 Sep;11(9):e0161126.

3. Shaw M, Black DW. Internet addiction: definition, assessment, epidemiology and clinical management. CNS Drugs. 2008;22(5):353-65.

4. Young KS. Internet addiction: the emergence of a new clinical disorder. Cyberpsychol Behav. 1998;1(3):237-44.

5. Abolghasem P, Eftekhari M, Rezania S, Jafarisani M, Soleimani R, Khalafi A. Studying the relationship between quality of sleep and addiction to internet among students. Nov J Med Biol Sci. 2016 Sep;5(3):1-7.

6. Reed P, Vile R, Osborne LA, Romano M, Truzoli R. Problematic internet usage and immune function. PLoS One. 2015 Aug;10(8):e0134538.

7. Shaw M, Black DW. Internet addiction: definition, assessment, epidemiology and clinical management. CNS Drugs. 2008;22(5):353-65. - ref. é igual a n. 3.

8. Widyanto L, Griffiths M. 'Internet addiction': a critical review. Int J Ment Health Addict. 2006;4(1):31-51.

9. Islam S, Rahman E, Moonajilin S, Griffiths D. Validation and evaluation of the psychometric properties of Bangla nine-item internet disorder scale-short form. J Addict Dis. 2020 Aug;38(4):540-9.

10. Khayat MA, Qari MH, Almutairi BS, Shuaib BH, Rambo MZ, Alrogi MJ, et al. Sleep quality and internet addiction level among university students. Egypt J Hosp Med. 2018 Oct; 73(7):7042-7.
11. Hasmujaj E. Internet addiction and loneliness among students of University of Shkodra. Eur Sci J. 2016 Oct;12(29):397-407.

12. Lam LT. Internet gaming addiction, problematic use of the internet, and sleep problems: a systematic review. Curr Psychiatry Rep. 2014 Apr;16(4):444.

13. Jahan MS, Hossain SR, Sayeed UB, Wahab A, Rahman T, Hossain A Association between internet addiction and sleep quality among students: a cross-sectional study in Bangladesh. Sleep Biol Rhythms. 2019;17:323-9.

14. Tan Y, Chen Y, Lu Y, Li L. Exploring associations between problematic internet use, depressive symptoms and sleep disturbance among southern Chinese adolescents. Int J Environ Res Public Health. 2016 Mar;13(3):313.

15. Islam A, Hossin MZ. Prevalence and risk factors of problematic internet use and the associated psychological distress among graduate students of Bangladesh. Asian J Gambl Issues Public Heal. 2016;6(1):11. DOI https://doi.org/10.1186/s40405-016-0020-1

16. Magnavita N, Garbarino S. Sleep, health and wellness at work: a scoping review. Int J Environ Res Public Health. 2017;14(11):1347.

17. Grandner MA. Sleep, health, and society. Sleep Med Clin. 2017 Mar;12(1):1-22.

18. Sahin S, Ozdemir K, Unsal A, Temiz N. Evaluation of mobile phone addiction level and sleep quality in university students. Pakistan J Med Sci. $2013 \mathrm{Jul} /$ Aug;29(4):913-8.

19. Thomée S, Härenstam A, Hagberg M. Mobile phone use and stress, sleep disturbances, and symptoms of depression among young adults-a prospective cohort study. BMC Public Health. 2011;11(1):66.

20. Khayat MA, Qari MH, Almutairi BS, Rambo MZ, Alrogi MJ, Alkhattabi SZ, et al. Sleep quality and internet addiction level among university students. Egypt J Hosp Med. 2018;73(7):7042-7. - ref. é igual a n. 10.

21. Kim SY, Kim MS, Park B, Kim JH, Choi HG. Lack of sleep is associated with internet use for leisure. PLoS One. 2018;13(1):e0191713.

22. Nagori N, Vasava K, Vala AU, Ratnani IJ. Association of sleep quality and internet addiction among the medical students. Int J Res Med Sci. 2019 $\mathrm{Jul} ; 7(7): 2703-7$.

23. Chen WL, Chen JH. Sleep deprivation and the development of leadership and need for cognition during the college years. J Adolesc. 2019 Jun;73:95-9.

24. Amaral AP, Soares MJ, Pinto AM, Pereira AT, Madeira N, Bos SC, et al. Sleep difficulties in college students: the role of stress, affect and cognitive processes. Psychiatry Res. 2018 Feb;260:331-7.

25. Rosen L, Carrier LM, Miller A, Rokkum J, Ruiz A. Sleeping with technology: cognitive, affective, and technology usage predictors of sleep problems among college students. Sleep Health. 2016 Mar;2(1):49-56.

26. Chen YL, Gau SSF. Sleep problems and internet addiction among children and adolescents: a longitudinal study. J Sleep Res. 2016 Aug;25(4):458-65.

27. Petrov ME, Lichstein KL, Baldwin CM. Prevalence of sleep disorders by sex and ethnicity among older adolescents and emerging adults: relations to daytime functioning, working memory and mental health. J Adolesc. 2014 Jul;37(5):587-97.

28. Howell AJ, Jahrig JC, Powell RA. Sleep quality, sleep propensity and academic performance. Percept Mot Skills. 2004 Oct;99(2):525-35.

29. Brown FC, Buboltz Junior WC, Soper B. Relationship of sleep hygiene awareness, sleep hygiene practices, and sleep quality in university students. Behav Med. 2002;28(1):33- 8 .

30. Pagel JF, Kwiatkowski CF. Sleep complaints affecting school performance at different educational levels. Front Neurol. 2010 Nov;1:125.

31. Mamun MA, Rafi MA, Al Mamun AHMS, Hasan MZ, Akter K, Hsan $\mathrm{K}$, et al. Prevalence and psychiatric risk factors of excessive internet use among Northern Bangladeshi job-seeking graduate students: a pilot study. Int J Ment Health Addict. 2019;1-11.

32. Ahmed S, Sen LC, Griffiths MD. Association between self-rated health and quality of life with sleep quality among Bangladeshi university students. Soc Health Behav. 2020;3(2):35-7.

33. Uddin S, Al Mamun A, Iqbal MA, Nasrullah M, Asaduzzaman M, Sarwar MS, et al. Internet addiction disorder and its pathogenicity to psychological distress and depression among university students: a crosssectional pilot study in Bangladesh. Psychology. 2016;7(8):1126.

34. Karim AKMR, Nigar N. The internet addiction test: assessing its psychometric properties in Bangladeshi culture. Asian J Psychiatr. 2014 Aug;10:75-83.

35. Buysse DJ, Reynolds CF, Monk TH, Berman SR, Kupfer DJ. The Pittsburgh sleep quality index: a new instrument for psychiatric practice and research. Psychiatry Res. 1989 May;28(2):193-213.

36. Mondal H, Mondal S, Baidya C. Comparison of perceived sleep quality among urban and rural adult population by Bengali Pittsburgh Sleep Quality Index. Adv Hum Biol. 2018 Jan;8(1):36.

37. Di Simone E, Fabbian F, Giannetta N, Dionisi S, Renzi E, Cappadona R, et al. Risk of medication errors and nurses' quality of sleep: a national cross-sectional web survey study. Eur Rev Med Pharmacol Sci. 2020 Jun;24(12):7058-62.

38. Young KS. Caught in the net: how to recognize the signs of internet addiction-and a winning strategy for recovery. New York: John Wiley \& Sons; 1998. 
39. Kim JH, Lau CH, Cheuk KK, Kan P, Hui HLC, Griffiths SM. Brief report: predictors of heavy Internet use and associations with healthpromoting and health risk behaviors among Hong Kong university students. J Adolesc. 2010 Feb;33(1):215-20.

40. Afandi O, Hawi H, Mohammed L, Salim F, Hameed AK, Shaikh RB, et al. Sleep quality among university students: evaluating the impact of smoking, social media use, and energy drink consumption on sleep quality and anxiety. Inq J. 2013;5(6):1-3.

41. Ak S, Koruklu N, Yılmaz Y. A study on Turkish adolescent's internet use: possible predictors of Internet addiction. Cyberpsychol Behav Soc Netw. 2013 Mar;16(3):205-9.

42. Mamun MA, Griffiths MD. Internet addiction and sleep quality: a response to Jahan et al. (2019). Sleep Biol Rhythms. 2019 Jul;17(4):463-4.
43. Lin PH, Lee YC, Chen KL, Hsieh PL, Yang SY, Lin YL. The relationships between sleep quality and internet addiction among female college students. Front Neurosci. 2019;13:599.

44. Ayran G, Gundogdu G, Işı1k NA. Effect of internet addiction on sleep quality in university students. Galician Med J. 2019;26(4):E201948.

45. Cheng SH, Shih CC, Lee IH, Hou YW, Chen KC, Chen KT, et al. A study on the sleep quality of incoming university students. Psychiatry Res. 2012 May;197(3):270-4.

46. Tavernier R, Willoughby T. Sleep problems: predictor or outcome of media use among emerging adults at university? J Sleep Res. 2014;23(4):389-96. Table 1. Socio-demographic and lifestyle factors among 400 university students. Table 1 . Socio-demographic and lifestyle factors among 400 university students. 